\title{
Dietary ascorbic acid and betaine improve stress responses, testosterone levels and some sexual traits in male Japanese quails during the dry season
}

\author{
Ifeanyichukwu Chukwuemeka Egbuniwe ${ }^{1, *}$ (D), Chukwuka Nwocha Uchendu ${ }^{2}$ and \\ Ikechukwu Reginald Obidike ${ }^{2}$ \\ ${ }^{1}$ Department of Veterinary Physiology and Biochemistry, University of Benin, Benin City, Nigeria, and ${ }^{2}$ Department of \\ Veterinary Physiology and Biochemistry, University of Nigeria, Nsukka, Nigeria \\ *Corresponding Author. E-mail: ifeanyiegbuniwe@gmail.com
}

(Received 13 May 2021; Accepted 30 May 2021)

\begin{abstract}
The experiment investigated the effects of dietary ascorbic acid and betaine stress responses, serum testosterone levels, and some sexual traits in male Japanese quails during the dry season. A total of 240 male Japanese quails (14 days old) were used and randomly assigned to four groups, each group has three replicates $(n=20)$. Birds in treatment groups were fed ascorbic acid (AA); betaine (BET); and AA + BET in their diets, whereas the control birds were fed only basal diet. Environmental conditions were predominantly outside thermoneutral zone for Japanese quails. Dietary AA \pm BET increased $(p<.05)$ serum catalase, reduced glutathione and testosterone, but lowered $(p<.05)$ cortisol levels when compared with control group. Supplemental AA, BET, or AA + BET enhanced $(p<.05)$ cloacal gland size and sexual traits. In conclusion, dietary AA and BET improved stress responses, serum testosterone levels, and some sexual traits in male Japanese quails during the dry season.
\end{abstract}

Keywords: antioxidants; heat stress; quails; sexual traits

\section{Introduction}

Japanese quails are good models for investigating testosterone regulation in sexual behavior, especially, in captive situation (Ball \& Balthazart, 2010). However, these quails are susceptible to heat stress conditions during the dry season in the tropics (Tuleun et al., 2013). Heat stress (which could be induced in poultry birds during the dry season) activates the hypothalamus-pituitary-adrenal (HPA) axis and elevates cortisol level due to elevated adrenocorticotropic hormone activity (Mormède et al., 2007). The increase in adrenocorticotropic activities depresses hypothalamus-pituitary-gonad axis and lowers testosterone in Japanese quails (Tsutsui et al., 2012). Antioxidant supplementation is used to ameliorate the adverse effects of heat stress on reproductive parameters of the quail (Abd El-Hack et al., 2020). In addition, some male sexual traits, such as size of cloacal gland and testes are useful indicators of reproductive potentials of male Japanese quails (Mohan et al., 2002).pt

\section{Objective}

Ascorbic acid (AA) is an antioxidant which scavenges stress-induced free radicals in poultry birds (Ismail et al., 2015). Betaine (BET) exerts methyl-donor, osmolyte (Amerah \& Ravindran, 2015) and antioxidant 
properties in poultry birds (Alirezaei et al., 2012). However, there is paucity of information on the effects of AA and BET supplementation on steroid activities and some sexual traits in male Japanese quails. The study is aimed at investigating effects of AA and BET supplementation on stress responses, testosterone levels, and some sexual traits in male Japanese quails during the dry season.

\section{Methods}

\subsection{Experimental site}

The experiment was performed during the dry season at the Animal House of Department of Veterinary Parasitology and Entomology, University of Nigeria, Nsukka (6 $52^{\prime} 0^{\prime \prime} \mathrm{N} ; 7^{\circ} 23^{\prime} \mathrm{E}$ ), in the Derived Savannah Ecological zone (Uguru et al., 2011).

\subsection{Ethical matters}

The methods of handling protocol were in accordance with the Animal Use and Care Committee of University of Nigeria, Nsukka, Nigeria. All quails were managed in accordance with the Guide for the Care and Use of Laboratory Animals (Committee on Care and Use of Laboratory Animals, 1996).

\subsection{Animals and experimental protocol}

A total of 240 male Japanese quail chicks; 14 days old and weighing $55.7 \pm 1.06 \mathrm{~g}$, were sourced commercially. A total of 240 male Japanese quail (14 days old; weighing $55.7 \pm 1.06 \mathrm{~g}$ ) were used and randomly assigned to four groups, each group has three replicate $(n=20$; Al-Salhie et al., 2017). Birds in each replicate were housed in spaces (91.44 cm length $\times 76.2 \mathrm{~cm}$ width $\times 91.4 \mathrm{~cm}$ height) within windowed animal pen and exposed to the natural environmental conditions. Birds were fed basal diets supplemented with AA (200 mg/kg; Sahin et al., 2002), BET (2 g/kg de Jong et al., 2012), and a combination of AA at $200 \mathrm{mg} / \mathrm{kg}$ and BET at $2 \mathrm{~g} / \mathrm{kg}$ (AA + BET) during the 49 days of study, whereas the control birds were administered basal diet only. AA used (Kempex Holland BV, Volkel, Netherlands) had a minimum purity of $99 \%$, whereas BET (Sigma-Aldrich, St. Louis, MO) was $\geq 99.0 \%$ purity. Daily dietary supplementation with AA and/or BET commenced after baseline serum testosterone values were established (when birds were 21 days old), and lasted 49 days (at 70 days old). Quails were given access to feeds and water ad-libitum.

\subsection{Measurements}

Thermal environmental conditions, measured as ambient temperature (AT) and relative humidity (RH) were recorded daily at 08:00 hr, 13:00 hr, and 17:00 hr throughout the study period. Blood collection was performed from six quails randomly selected and identified from each group at 21, 28, 49, and 70 days old. Blood samples were centrifuged at 3,000 g for $10 \mathrm{~min}$ (El-Tarabany, 2016) sera were harvested and immediately analyzed. Indicators of stress such as serum catalase (KU/L) and reduced glutathione (nMoles/ml) were determined spectrophotometrically, but cortisol $(\mu \mathrm{g} / \mathrm{dl})$; using enzyme-linked immunosorbent assay technique. Testosterone levels were determined using the microplate enzyme immunoassay kit (Monobind Incorporated, Lake Forest, CA). At 28, 49, and 70 days of age, sexual traits of quails randomly selected from each group were determines by measuring cloacal gland size $(n=12)$ and indices of testicular development $(n=4)$ such as paired testicular weight, left testicular area, and combined testicular volume. Index of gland size (or area) was determined by the product of cloacal gland width and height, and expressed in $\mathrm{cm}^{2}$ (Siopes \& Wilson, 1975). The formulas described by Chaturvedi et al. (1993) was used to calculate cloacal volume, expressed in $\mathrm{cm}^{3}$ :

$4 / 3 \times 3.5414 \times a \times b^{2}$ (where $a=0.5 \times$ long axis and $b=0.5 \times$ short axis). 
Measurements of length and width of left and right testes were taken to the nearest $0.01 \mathrm{~mm}$ using digital vernier caliper (Shanghai Techway Industrial Co., Ltd., Shanghai City, China). Bissonett's formula was used to evaluate testicular volume: $4 / 3 \pi a b^{2}$ ( $a=$ half of the long axis and $b=$ half of the short axis), and expressed in $\mathrm{cm}^{3}$ (Banerjee \& Chaturvedi, 2017).

\subsection{Statistical analysis}

Data obtained are expressed as mean \pm standard error of mean. The values were subjected to statistical analysis and compared using analysis of variance (ANOVA), followed by Tukey's post-hoc test. Values of $p<.05$ were considered significant (Snedecor \& Cochran, 1994). GraphPad Prism (GraphPad Software, Incorporated, San Diego, CA) version 6.0 was for analysis.

\section{Results}

\subsection{Thermal environmental conditions}

The range values of AT were $25.0-37.0^{\circ} \mathrm{C}$, whereas those of $\mathrm{RH}$ were from 48.0 to $92.0 \%$ during the experimental period (Figure 1).

\subsection{Indicators of stress}

All serum catalase, reduced glutathione, and testosterone levels were higher $(p<.05)$ in the groups treated with $\mathrm{AA} \pm \mathrm{BET}$, whereas cortisol levels were lower $(p<.05)$ when compared with the control group (Table 1).

\subsection{Serum testosterone levels}

Serum testosterone concentrations were not detected at 21 days old in all the groups. In all groups (control and $\mathrm{AA} \pm \mathrm{BET}$ ), serum testosterone levels were increased as the birds grew older. This trend is observed in higher $(p<.05)$ serum testosterone levels in birds at 49 and 70 days old when compared with when they were 28 days old in each of the experimental groups. At 28 and 49 days old, serum testosterone levels in quails that are fed with either enriched AA, BET, or AA + BET were higher $(p<.05)$ when compared with values recorded in control group. Testosterone levels increased $(p<.05)$ in birds fed either $\mathrm{AA}$ or $\mathrm{AA}+\mathrm{BET}$ in their diets when compared with control at 70 days old (Figure 2).

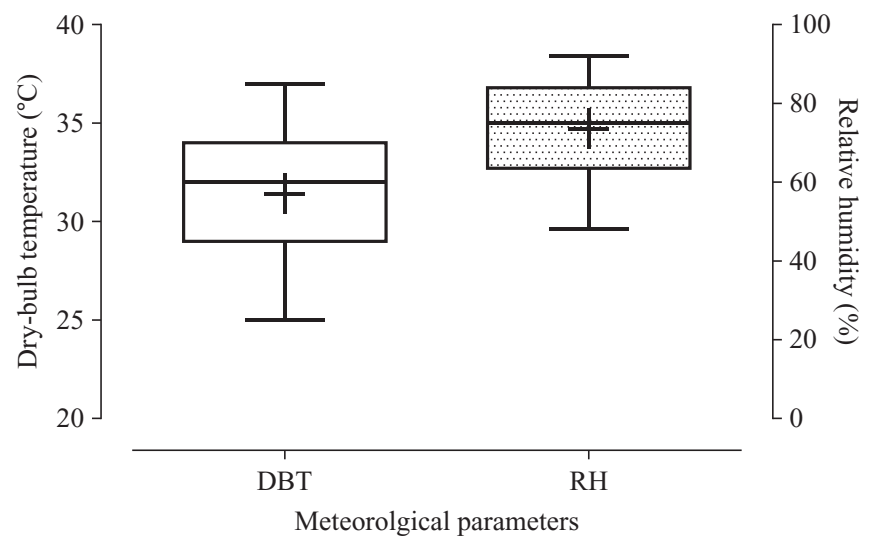

Figure 1. Boxplot describing micro-environmental conditions within the poultry house during the study period. DBT, dry bulb temperature $\left({ }^{\circ} \mathrm{C}\right) ; \mathrm{RH}$, relative humidity $(\%)$. 
Table 1. Indicators of stress in Japanese quails reared during the dry season $(n=6)$

\begin{tabular}{lcccc} 
& \multicolumn{4}{c}{ Experimental groups } \\
\cline { 2 - 5 } Stress indicators & Control & AA & BET & AA + BET \\
\hline Catalase $(\mathrm{KU} / \mathrm{L})$ & $32.4 \pm 2.0^{\mathrm{a}}$ & $51.6 \pm 3.3^{\mathrm{b}}$ & $45.4 \pm 1.3^{\mathrm{b}}$ & $47.1 \pm 2.1^{\mathrm{b}}$ \\
\hline Reduced glutathione $(\mathrm{nMol} / \mathrm{ml})$ & $6.2 \pm 0.4^{\mathrm{a}}$ & $8.2 \pm 0.4^{\mathrm{b}}$ & $8.2 \pm 0.5^{\mathrm{b}}$ & $8.6 \pm 0.4^{\mathrm{b}}$ \\
\hline Cortisol $(\mu \mathrm{g} / \mathrm{dl})$ & $1.0 \pm 0.2^{\mathrm{a}}$ & $0.7 \pm 0.2^{\mathrm{a}}$ & $0.5 \pm 0.1^{\mathrm{b}}$ & $0.5 \pm 0.1^{\mathrm{b}}$ \\
\hline
\end{tabular}

Abbreviations: AA, ascorbic acid; AA + BET, combination of ascorbic acid and betaine included in diets; BET, betaine; Control, basal diet.

${ }^{\mathrm{a}, \mathrm{b}}$ Mean values with different superscript letters within the same row are significantly different $(p<.05)$.

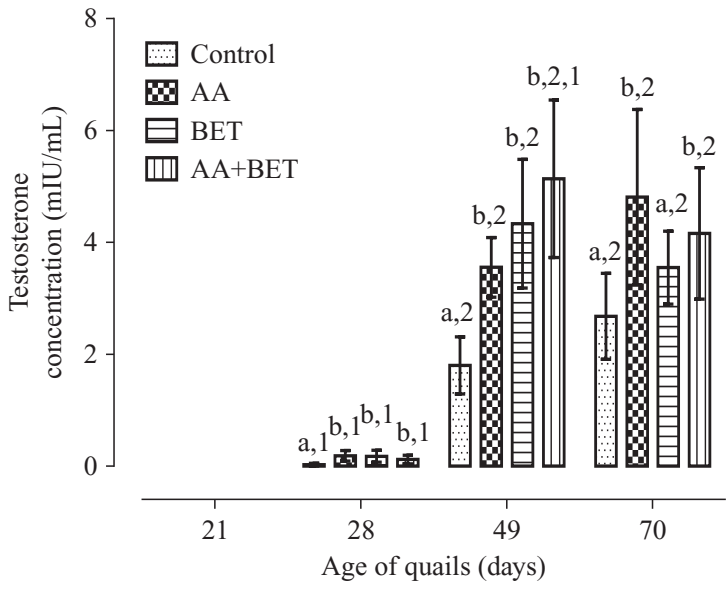

Figure 2. Changes in serum concentration of testosterone with age of Japanese quails during the study period. Control, basal diet; AA, ascorbic acid; BET, betaine; and AA + BET, combination of ascorbic acid and betaine included in diets. ${ }^{\mathrm{a}, \mathrm{b}, 1,2}$ Mean values with different superscript letters and numbers between and within groups, respectively, are significantly different $(p<.05)$.

\subsection{Sexual traits of male quails}

Cloacal gland area increased $(p<.05)$ in the treated quails when compared with those of the control, especially, in 28 days old birds. In addition, cloacal volume was higher $(p<.05)$ in the treated quails when compared with values obtained in the control, especially at 28 and 49 days of age. Furthermore, quails of the treated group recorded increased $(p<.05)$ paired testicular weight when compared with birds of control group at 28 days old. Testicular area and combined volume were higher $(p<.05)$ at 28 and 49 days old, when compared with the corresponding values obtained in the control group (Table 2 ).

\section{Discussion}

\subsection{Thermal environmental conditions}

The results of the present study indicate that the recorded AT and RH fluctuated widely and predominantly exceeded the thermoneutral zone for Japanese quails. The thermoneutral zone for quails are $23.8 \pm 0.7^{\circ} \mathrm{C}$ for AT and $58.5 \pm 5.7 \%$ for RH (El-Tarabany, 2016). Thus, the results of the current study suggest that the natural environmental conditions during the dry season are potentially stressful for Japanese quails. The findings of the present study agree with those of Minka and Ayo (2013), who showed that the dry season in the Northern Guinea Savannah, with mean AT and RH of $32.5 \pm 1.4^{\circ} \mathrm{C}$ and $66.9 \pm 5.7 \%$, respectively, were stressful to Japanese quails. In addition, Mehaisen et al. (2017) demonstrated that AT values exceeding $30^{\circ} \mathrm{C}$ may be stressful for Japanese quails (Mehaisen et al., 
Table 2. Variations in sizes of cloacal gland and testes in male Japanese quails during the dry season

\begin{tabular}{|c|c|c|c|c|c|}
\hline \multirow{2}{*}{$\begin{array}{l}\text { Cloacal gland } \\
\text { parameters }\end{array}$} & \multirow{2}{*}{$\begin{array}{c}\text { Age of } \\
\text { birds (days) }\end{array}$} & \multicolumn{4}{|c|}{ Experimental groups } \\
\hline & & Control & $A A$ & BET & $\mathrm{AA}+\mathrm{BET}$ \\
\hline \multirow[t]{3}{*}{$\begin{array}{l}\text { Cloacal gland area } \\
\qquad\left(n=12 ; \mathrm{cm}^{2}\right)\end{array}$} & 28 & $0.43 \pm 0.07^{a, 1}$ & $0.85 \pm 0.12^{\mathrm{b}, 1}$ & $0.73 \pm 0.09^{b, 1}$ & $0.85 \pm 0.11^{\mathrm{b}, 1}$ \\
\hline & 49 & $1.33 \pm 0.11^{\mathrm{a}, 2,1}$ & $2.32 \pm 0.28^{\mathrm{b}, 2,1}$ & $2.00 \pm 0.15^{\mathrm{a}, 2,1}$ & $1.96 \pm 0.35^{\mathrm{a}, \mathrm{b}, 2,1}$ \\
\hline & 70 & $2.67 \pm 0.30^{\mathrm{a}, 2}$ & $3.30 \pm 0.15^{\mathrm{a}, 2}$ & $3.36 \pm 0.11^{\mathrm{a}, 2}$ & $3.75 \pm 0.23^{\mathrm{a}, 2}$ \\
\hline \multirow[t]{3}{*}{$\begin{array}{l}\text { Cloacal gland volume } \\
\qquad\left(n=12 ; \mathrm{cm}^{3}\right)\end{array}$} & 28 & $1.18 \pm 0.28^{\mathrm{a}, 1}$ & $3.54 \pm 0.74^{b, 1}$ & $2.66 \pm 0.47^{\mathrm{b}, 1}$ & $3.46 \pm 0.65^{b, 1}$ \\
\hline & 49 & $6.34 \pm 0.77^{\mathrm{a}, 1}$ & $14.85 \pm 2.57^{\mathrm{b}, 2,1}$ & $11.05 \pm 1.57^{\mathrm{b}, 2,1}$ & $11.86 \pm 3.29^{b, 1}$ \\
\hline & 70 & $19.09 \pm 2.54^{\mathrm{a}, 2}$ & $25.63 \pm 1.57^{a, 2}$ & $26.32 \pm 1.62^{\mathrm{a}, 2}$ & $32.43 \pm 3.10^{\mathrm{b}, 2}$ \\
\hline \multirow[t]{3}{*}{$\begin{array}{l}\text { Paired Testicular } \\
\text { weight }(n=4 ; \mathrm{g})\end{array}$} & 28 & $0.02 \pm 0.01^{a, 1}$ & $0.12 \pm 0.7^{b, 1}$ & $0.06 \pm 0.01^{\mathrm{b}, \mathrm{a}, 1}$ & $0.13 \pm 0.06^{\mathrm{b}, 1}$ \\
\hline & 49 & $2.77 \pm 0.94^{\mathrm{a}, 2}$ & $3.28 \pm 0.25^{\mathrm{a}, 2}$ & $3.57 \pm 0.59^{\mathrm{a}, 2}$ & $3.61 \pm 0.47^{\mathrm{a}, 2,1}$ \\
\hline & 70 & $4.40 \pm 0.26^{\mathrm{a}, 2}$ & $3.82 \pm 0.22^{\mathrm{a}, 2}$ & $4.63 \pm 0.37^{\mathrm{a}, 2}$ & $4.93 \pm 0.25^{\mathrm{a}, 2}$ \\
\hline \multirow[t]{3}{*}{$\begin{array}{l}\text { Left testes area }(n=4 ; \\
\left.\qquad \mathrm{cm}^{2}\right)\end{array}$} & 28 & $0.19 \pm 0.07^{\mathrm{a}, 1}$ & $0.40 \pm 0.09^{\mathrm{b}, 1}$ & $0.27 \pm 0.05^{a, 1}$ & $0.38 \pm 0.08^{\mathrm{b}, 1}$ \\
\hline & 49 & $1.91 \pm 0.34^{\mathrm{a}, 2,1}$ & $2.61 \pm 0.12^{\mathrm{b}, 2}$ & $2.87 \pm 0.42^{\mathrm{b}, 2}$ & $2.86 \pm 0.07^{\mathrm{b}, 2}$ \\
\hline & 70 & $3.19 \pm 0.21^{\mathrm{a}, 2}$ & $2.89 \pm 0.13^{\mathrm{a}, 2}$ & $3.83 \pm 0.30^{\mathrm{a}, 2}$ & $3.42 \pm 0.19^{\mathrm{a}, 2}$ \\
\hline \multirow[t]{3}{*}{$\begin{array}{l}\text { Combined testicular } \\
\quad \text { volume }\left(n=4 ; \mathrm{cm}^{3}\right)\end{array}$} & 28 & $0.05 \pm 0.03^{a, 1}$ & $0.21 \pm 0.06^{\mathrm{b}, 1}$ & $0.11 \pm 0.02^{\mathrm{b}, 1}$ & $0.17 \pm 0.05^{\mathrm{b}, 1}$ \\
\hline & 49 & $2.43 \pm 0.79^{a, 2}$ & $3.70 \pm 0.34^{\mathrm{b}, 2,1}$ & $3.57 \pm 0.64^{\mathrm{b}, 2}$ & $3.65 \pm 0.41^{\mathrm{a}, 2}$ \\
\hline & 70 & $4.40 \pm 0.22^{\mathrm{a}, 2}$ & $3.84 \pm 0.21^{\mathrm{a}, 2}$ & $5.24 \pm 0.31^{\mathrm{a}, 1,2}$ & $5.22 \pm 0.42^{a, 2}$ \\
\hline
\end{tabular}

Abbreviations: AA, ascorbic acid; AA + BET, combination of ascorbic acid and betaine included in diets; BET, betaine; Control, basal diet. ${ }^{a, b, 1,2}$ Mean values with different superscript letters and numbers between and within groups, respectively, are significantly different $(p<.05)$.

2017). The high AT and RH which prevailed during the dry season, when the present study was conducted, have detrimental to the health, welfare, and reproductive performance of Japanese quails.

\subsection{Heat stress and indicators of stress}

The result of the present study demonstrates that supplementations with AA and/or BET in diets of male Japanese quails improved serum antioxidant enzyme activities when reared during the thermally stressful dry season. The findings of the present study agrees with those of Alirezaei et al. (2012) who demonstrated that BET improved the antioxidant status of meat of broiler chicken subjected to heat stress conditions. Khan et al. (2012) also showed that AA plays a role in enhancing antioxidant defenses in poultry birds. The findings of the current study suggest that AA and BET supplementation would enhance antioxidant defenses and improve thermotolerance in Japanese quails during the dry season.

\subsection{Heat stress and testosterone levels}

The results of the current study show testosterone synthesis in testes may have been too minimal to be detected at 21 days old male Japanese quails. The inability to detect testosterone at 21 days of age could be due to heat stress-induced delay in sexual maturity. The developmental phases of quails are classified as 
chick (0-21 days [or 0-3 weeks]); grower (28-35 days [or 4-5 weeks]); and adult (above 35 days [or 5 weeks]; Puspamitra et al., 2018). The results of the present study are in agreement with Min et al., 2016, who showed stress results in decline in testosterone levels in serum, but that AA and vitamin E ameliorated this decline in rooster breeders. Parisi and Guerriero (2019) showed that sex steroids, such as testosterone, are susceptible to oxidative stress due to thermal stress. The susceptibility of testosterone to the deleterious effects of free radicals requires antioxidants to ameliorate these effects (Sahin et al., 2017). The increased serum testosterone observed in the present study in birds fed dietary AA, both alone and it combination with BET, may be attributed to the antioxidant potentials of AA, acting in synergy with the methyl donor properties of betaine, when incorporated in the diets of male Japanese quails. These mechanisms of action of AA and BET could be beneficial to improve gonadal activities, libido, and fertility in male Japanese quails when exposed to the thermally stressful dry season.

\subsection{Stress and sexual traits}

The findings of the current study indicate that the size of cloacal gland increased in birds of the treated groups. The results of the present study agree with those of Biswas et al. (2017) who demonstrated that selenium, an antioxidant, incorporated in diets of Japanese quails increased the size of cloacal gland and production of cloacal foam. Biswas et al. (2007) also showed vitamin E improved cloacal gland size. Cloacal gland is a peculiar anatomical feature of Coturnix quails which is an indication of testicular size and function. Therefore, the assessment of cloacal gland size is referred to as a noninvasive tool to evaluate testicular activity and maturity in Japanese quails (Dominchin et al., 2016, 2017). Momoh et al., (2014) showed that the age of sexual maturity in Japanese quails reared under hot-humid condition is 56 weeks old. The present study did not evaluate the age of sexual maturity. This is one limitation of the present study. However, the result of the present study suggests that the bigger cloacal gland observed in AA and/or BET fed quails when compared with control group could be due to antioxidant effects of AA and BET on testosterone activity.

Similarly, the results of the present study show that testicular development increased with increase in age, especially, in those fed diets enriched with AA, alone and its combination with BET. The findings of the present study agree with those of Tsutsui et al. (2015), who demonstrated that rosemary oil exerted antioxidant protection against oxidative damage in the testes of heat-stressed Japanese quails. Heat stress-induced lipid peroxidation may result in developmental and functional damages in testes (Türk et al., 2016). It is suggested that improved testicular development in male quails fed diets enriched with AA and/or BET in the present study could improve fertility during the dry season. The results of the current study and its potential benefits to reproductive responses in the birds corroborate with those of Egbuniwe et al., 2020, who demonstrated that diets enriched with BET and AA promote reproductive potentials as well as, sex and stress hormones (Egbuniwe et al., 2021) in Japanese quails during the dry season.

The results of this study may be useful to quail breeders who could use AA and BET to ameliorate heat stress effects on male sexual traits and optimize reproductive performance of male quails reared during the dry season.

\section{Conclusion}

From the results of the current study, it is demonstrated that heat stress conditions prevailing during the dry season in the zone adversely impact on some sexual traits of male Japanese quails. However, dietary enrichments with AA and/or BET could be utilized to ameliorate the negative impacts of dry seasoninduced heat stress in male Japanese quails. In conclusion, dietary AA and BET improve steroidal responses and some sexual traits in male Japanese quails during the dry season.

Acknowledgment. The authors thank Drs. Oguejiofor, Akogwu, and Obetta for their assistance during the period of the current study. 
Funding statement. None to declare.

Conflict of interest. The authors declare no conflict of interest.

Data availability statement. The data that support the findings of this study will be openly made available in University of Nigeria, Nsukka Repository at https://oer.unn.edu.ng/reports?rdr=1.

\section{References}

Abd El-Hack, M., Abdelnour, T. A., Khafagad, A., Arif, M., Ayasan, T., \& Abdel-Daim, M. (2020). Herbs as thermoregulatory agents in poultry: An overview. Science of the Total Environment, 703, 134399. doi:10.1016/j.scitotenv.2019.134399.

Alirezaei, M., Gheisari, H. R., Ranjbar, V. R., \& Hajibemani, A. (2012). Betaine: A promising antioxidant agent for enhancement of broiler meat quality. British Poultry Science, 53, 699-707.

Al-Salhie, K. C., Sabah, K. M., \& Rabia, J. A. (2017). Effect of supplementation different levels of vitamin E and pumpkin seed oil to the diet on productive, physiological and reproductive performance of Japanese quail. Basrah Journal of Agricultural Science, 30, 50-58.

Amerah, A. M., \& Ravindran, V. (2015). Effect of coccidia challenge and natural betaine supplementation on performance, nutrient utilization, and intestinal lesion scores of broiler chickens fed suboptimal level of dietary methionine. Poultry Science, 94, 673-680.

Ball, G. F., \& Balthazart, J. (2010). Japanese quail as a model system for studying the neuroendocrine control of reproductive and social behaviors. The Institute for Laboratory Animal Research, 51, 310-325.

Banerjee, S., \& Chaturvedi, C. (2017). Testicular atrophy and reproductive quiescence in photorefractory and scotosensitive quail: Involvement of hypothalamic deep brain photoreceptors and GnRH-GnIH system. Journal of Photochemistry Photobiology B, 175, 254-268.

Biswas, A., Mohan, J., Mandal, A. B., \& Lal, N. (2017). Semen characteristics and biochemical composition of cloacal foam of male Japanese quails (Coturnix coturnix japonica) fed diet incorporated with selenium. Journal of Animal Physiology \& Animal Nutrition, 101, 229-235.

Biswas, A., Mohan, J., Sastry, K. V. H., \& Tyagi, J. S. (2007). Effect of dietary vitamin E on the cloacal gland, foam and semen characteristics of male Japanese quail. Theriogenology, 67, 259-263.

Chaturvedi, C. M., Bhatt, R., \& Phillips, D. (1993). Photoperiodism in Japanese quail (Coturnix coturnix japonica) with special reference to relative refractoriness. Indian Journal of Experimental Biology, 31, 417-421.

Committee on Care and Use of Laboratory Animals. (1996). Guide for the Care and Use of Laboratory Animals. In National Research Council, Institute of Laboratory Animal Resources Commission on Life Sciences. Washington, DC: National Academy Press.

de Jong, I., Berg, C., Butterworth, A., \& Estevéz, I. (2012). Scientific report updating the EFSA opinions on the welfare of broilers and broiler breeders. European Food Safety Agency Journal, 9, 116.

Dominchin, M. F., Busso, J. M., Kembro, J. M., Marin, R. H., \& Guzmán, D. A. (2016). Divergent cloacal gland photoresponsiveness in male Japanese quail exposed to short days and associated differences in social interactions and reproduction. Poultry Science, 96, 5-13.

Dominchin, M.F., Busso, J.M., Kembro, J.M., Marin, R.H., \& Guzmán, D.A. (2017). Divergent cloacal gland photoresponsiveness in male Japanese quail exposed to short days and associated differences in social interactions and reproduction. Poultry Science, 96(1), 5-13.

Egbuniwe, I. C., Uchendu, C. N., \& Obidike, I. R. (2020). Effects of betaine and ascorbic acid supplementation on serum gonadotropin, testicular histological analysis and sperm quality in male Japanese quails during the dry season. Theriogenology, 158, 391-405.

Egbuniwe, I. C., Uchendu, C. N., \& Obidike, I. R. (2021). Ameliorative effects of betaine and ascorbic acid on endocrine and erythrocytic parameters of sexually-maturing female Japanese quails during the dry season. Journal of Thermal Biology, 96, 102812.

El-Tarabany, M. (2016). Impact of temperature-humidity index on egg-laying characteristics and related stress and immunity parameters of Japanese quails. International Journal of Biometeorology, 60, 957-964.

Ismail, I. B., Al-Busadah, K. A., \& El-Bahr, S. M. (2015). Biochemical markers of oxidative stress in tissues of broiler chickens fed zinc bacitracin and ascorbic acid under hot climate. International Journal of Biology and Chemical Sciences, 9, 38-45.

Khan, R. U., Naz, S., Nikousefat, Z., Selvaggi, M., Laudadio, V., \& Tufarelli, V. (2012). Effect of ascorbic acid in heat-stressed poultry. World's Poultry Science Journal, 68, 477-490.

Mehaisen, G. M., Ibrahim, R. M., Desoky, A. A., Safaa, H. M., El-Sayed, O. A., \& Abass, A. O. (2017). The importance of propolis in alleviating the negative physiological effects of heat stress in quail chicks. Public Library of Science, One12, e0186907. https://doi.org/10.1371/journal.pone.0186907.

Min, Y., Sun, T., Niu, Z., \& Liu, F. (2016). Vitamin C and vitamin E supplementation alleviates oxidative stress induced by dexamethasone and improves fertility of breeder roosters. Animal Reproduction Science, 171, 1-6. 
Minka, N. S., \& Ayo, J. O. (2013). Effects of antioxidants Vitamin E and C on erythrocyte fragility, haemoglobinindex and colonic temperature of transported Japanese quails (Coturnix coturnix japonica). Veterinary Science and Technology, 4, 1.

Mohan, J., Moudgal, R. P., Sastry, K. V. H., Tyagi, J., \& Singh, R. (2002). Effects of hemicastration and castration on foam production and its relationship with fertility in male Japanese quail. Theriogenology, 58, 29-39.

Momoh, O. M., Gambo, D., \& Dim, N. I. (2014). Genetic parameters of growth, body, and egg traits in Japanese quails (Coturnix coturnix japonica) reared in southern guinea savannah of Nigeria. Journal of Applied Biosciences, 79, 6947-6954.

Mormède, P., Andanson, S., Aupérin, B., Beerda, B., Guémené, D., Malmkvist, J., \& Richard, S. (2007). Exploration of the hypothalamic-pituitary-adrenal function as a tool to evaluate animal welfare. Physiology of Behaviour, 92, 317-339.

Parisi, C., \& Guerriero, G. (2019). Antioxidative defense and fertility rate in the assessment of reprotoxicity risk posed by global warming. Antioxidants, 8, 622.

Puspamitra, S., Mohanty, P.K. \& Mallik, B.K. (2018). Haemocytomorphometric variation in different ages of Japanese quail. Comparative Clinical Pathology 27, 847-853.

Sahin, K., Sahin, N., \& Yaralıglu, S. (2002). Effects of vitamin C and vitamin E on lipid peroxidation, blood serum metabolites and mineral concentrations of laying hens reared at high ambient temperature. Biological Trace Element Research, 85, 35-45.

Sahin, N., Orhan, C., Tuzcu, M., Juturu, V., \& Sahin, K. (2017). Capsaicinoids improve egg production by regulating ovary nuclear transcription factors against heat stress in quail. British Poultry Science, 58, 177-183.

Siopes, T. D., \& Wilson, W. O. (1975). The cloacal gland: An external indicator of testicular development in coturnix. Poultry Science, 54, 1225-1229.

Snedecor, G., \& Cochran, W. G. (1994) Statistical methods (8th ed.). Calcutta, India: Oxford and IBH.

Tsutsui, K., Ubuka, T., Bentley, G. E., \& Kriegsfeld, L. J. (2012). Gonadotropin-inhibitory hormone (GnIH): Discovery, progress and prospect. General and Comparative Endocrinology, 177, 305-314.

Tsutsui, K., Ubuka, T., Son, Y. L., Bentley, G. E., \& Kriegsfeld, L. J. (2015). Contribution of GnIH research to the progress of reproductive neuroendocrinology. Frontier in Endocrinology, 6, 14.

Tuleun, C. D., Adenkola, A. Y., \& Yenle, F. G. (2013). Performance and erythrocyte osmotic membrane stability of laying Japanese quails (Coturnix coturnix japanica) fed varying dietary protein levels in a hot-humid tropics. Agriculture and Biology Journal of North America, 4, 6-13.

Türk, G., Çeribaşı, A. O., Şimşek, Ü. G., Çeribaşı, S., Güvenç, M., Kaya, Ş. Ö., \& Yaman, M. (2016). Dietary rosemary oil alleviates heat stress-induced structural and functional damage through lipid peroxidation in the testes of growing Japanese quail. Animal Reproduction Science, 164, 133-143.

Uguru, M., Baiyeri, K., \& Aba, S. (2011). Indicators of climate change in the derived savannah Niche of Nsukka, South-Eastern Nigeria. Agro-Science, 10, 17-26. https://doi.org/10.4314/as.v10i1.68718.

Cite this article: Egbuniwe IC, Uchendu CN, Obidike IR (2021). Dietary ascorbic acid and betaine improve stress responses, testosterone levels and some sexual traits in male Japanese quails during the dry season Experimental Results, 2, e23, 1-11. https://doi.org/10.1017/exp.2021.10 


\section{Peer Reviews}

\section{Reviewing editor: Prof. Martin Michaelis}

University of Kent, School of Biosciences, Canterbury, United Kingdom of Great Britain and Northern Ireland, CT2 7NJ

This article has been accepted because it is deemed to be scientifically sound, has the correct controls, has appropriate methodology and is statistically valid, and has been sent for additional statistical evaluation and met required revisions.

doi:10.1017/exp.2021.10.pr1

Review 1: Dietary ascorbic acid and betaine improve stress responses, testosterone levels and some sexual traits in male Japanese quails during the dry season

Reviewer: Dr. Tuncay Tufan (iD

Siirt University

Date of review: 28 May 2021

(C) The Author(s), 2021. Published by Cambridge University Press. This is an Open Access article, distributed under the terms of the Creative Commons Attribution licence (http://creativecommons.org/licenses/by/4.0), which permits unrestricted re-use, distribution and reproduction, provided the original article is properly cited.

Conflict of interest statement. I did a peer review for this article. I do not have any conflict of interest.

Comments to the Author: It is understood that a correction was made by the author in this research article. It is recommended to rewrite the title, associating it with "heat stress". In the "Materials and Methods" section, it is recommended to write the method a little bit abbreviated. Also, due to the low number of results in this article, it is recommended to be published as "short communication".

\section{Score Card}

Presentation

3.3

Is the article written in clear and proper English? (30\%)

Is the data presented in the most useful manner? (40\%)

Does the paper cite relevant and related articles appropriately? (30\%)

\section{Context}

Does the title suitably represent the article? (25\%)

Does the abstract correctly embody the content of the article? (25\%)

Does the introduction give appropriate context? (25\%)

Is the objective of the experiment clearly defined? (25\%) 
Analysis

Is the conclusion consistent with the results and discussion? (40\%)

Are the limitations of the experiment as well as the contributions of the experiment clearly outlined? (20\%) 
Review 2: Dietary ascorbic acid and betaine improve stress responses, testosterone levels and some sexual traits in male Japanese quails during the dry season

Reviewer: Dr. Mehran Mehri

University of Zabol, Animal Science, Zabol, Iran (the Islamic Republic of)

Date of review: 26 May 2021

(c) The Author(s), 2021. Published by Cambridge University Press. This is an Open Access article, distributed under the terms of the Creative Commons Attribution licence (http://creativecommons.org/licenses/by/4.0), which permits unrestricted re-use, distribution and reproduction, provided the original article is properly cited.

Conflict of interest statement. Reviewer declares none.

Comments to the Author: This manuscript has been written very poor and needs to be thoroughly revised by native English speaker. A lot of grammatical syntax issues are in the text that should be amended before scientific revision.

\section{Score Card}

\section{Presentation}

1.9

Is the article written in clear and proper English? (30\%)

Is the data presented in the most useful manner? (40\%)

Does the paper cite relevant and related articles appropriately? (30\%)

Context

Does the abstract correctly embody the content of the article? (25\%)

Does the introduction give appropriate context? (25\%)

Is the objective of the experiment clearly defined? (25\%)

Analysis

1.4

Does the discussion adequately interpret the results presented? (40\%)

Is the conclusion consistent with the results and discussion? (40\%)

Are the limitations of the experiment as well as the contributions of the experiment clearly outlined? (20\%) 